\title{
Auditoria qualitativa do risco de queda por meio da escala Johns Hopkins
}

\author{
Juliana Miyuki do Prado ${ }^{1}$ \\ Silvia Helena Frota Mendonça ${ }^{2}$ \\ Maristhela Sonchine Urquiza Almeida ${ }^{3}$ \\ Denise Cavallini Alvarenga ${ }^{4}$
}

\section{Introdução}

Em hospitais, quedas de pacientes podem provocar danos graves, além de contribuir para o aumento do tempo de permanência e custos assistenciais. A avaliação do risco de queda por meio de escalas é uma ferramenta utilizada para direcionamento de ações preventivas.

Após 8 meses de mudança para escala Johns Hopkins Fall Risk Assessment Tool (JHFRAT) não houve diminuição significativa da incidência de queda da instituição, portanto, deveríamos investigar a conformidade na aplicação da escala nas unidades de internação adulto.

A Escala JHFRAT possui duas formas de classificar o paciente, a primeira, por meio de situações definidoras do risco, e a segunda, por meio de aplicação de pontuações de critérios pré definidos.

A hipótese investigada foi se haveria divergência na aplicação dos critérios pelos Enfermeiros.

\section{Objetivo}

Realizar Auditoria Qualitativa da classificação do Risco de Queda nas unidades de internação adulto.

\section{Método}

Foi feita Auditoria qualitativa da classificação do risco de queda em unidades de internação de adulto, com a avaliação do registro em Prontuário Eletrônico no mês de Fevereiro de 2018.

Verificado a conformidade do uso da escala por meio da análise dos fatores de risco do paciente (medicamentos em uso, dispositivos, idade, marcha, mobilidade, eliminações e cognição), e a comparação do registro da avaliação feita pelo Enfermeiro da unidade com a classificação do auditor.

Foi considerado "Conforme" quando todas as categorias pontuadas pelo auditor foram exatamente as mesmas pontuadas pela unidade e "Parcialmente Conforme" quando, no mínimo uma categoria, diferia entre avaliação do auditor e enfermeiro da unidade.

\section{Resultados}

Foram avaliados 204 dias em 19 pacientes. Apenas 15,2\% de conformidade foi encontrada; $12,3 \%$ de dias sem avaliação do risco pelas unidades e $72,5 \%$ Parcialmente conforme. Das não conformidades encontradas, $64,2 \%$ alteraram a classificação do risco de queda, sendo $38,9 \%$ mudando de risco moderado para alto risco de queda.

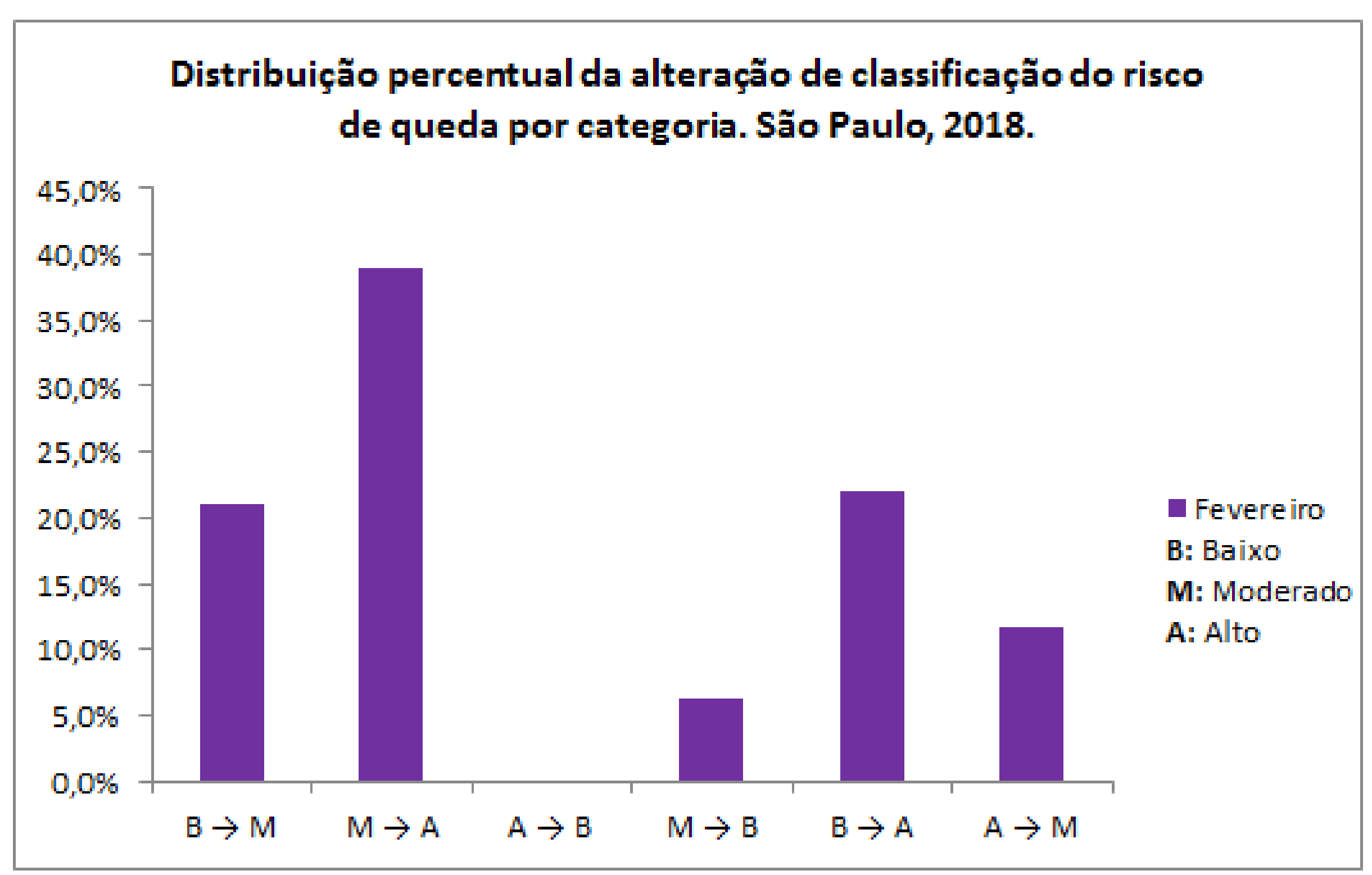

As principais causas identificadas foram: erro na utilização do critério e falta de definição de algumas categorias da escala. A partir dos resultados foram definidos e validados os protocolos específicos de acordo com o perfil da instituição e realizado o detalhamento de cada categoria.

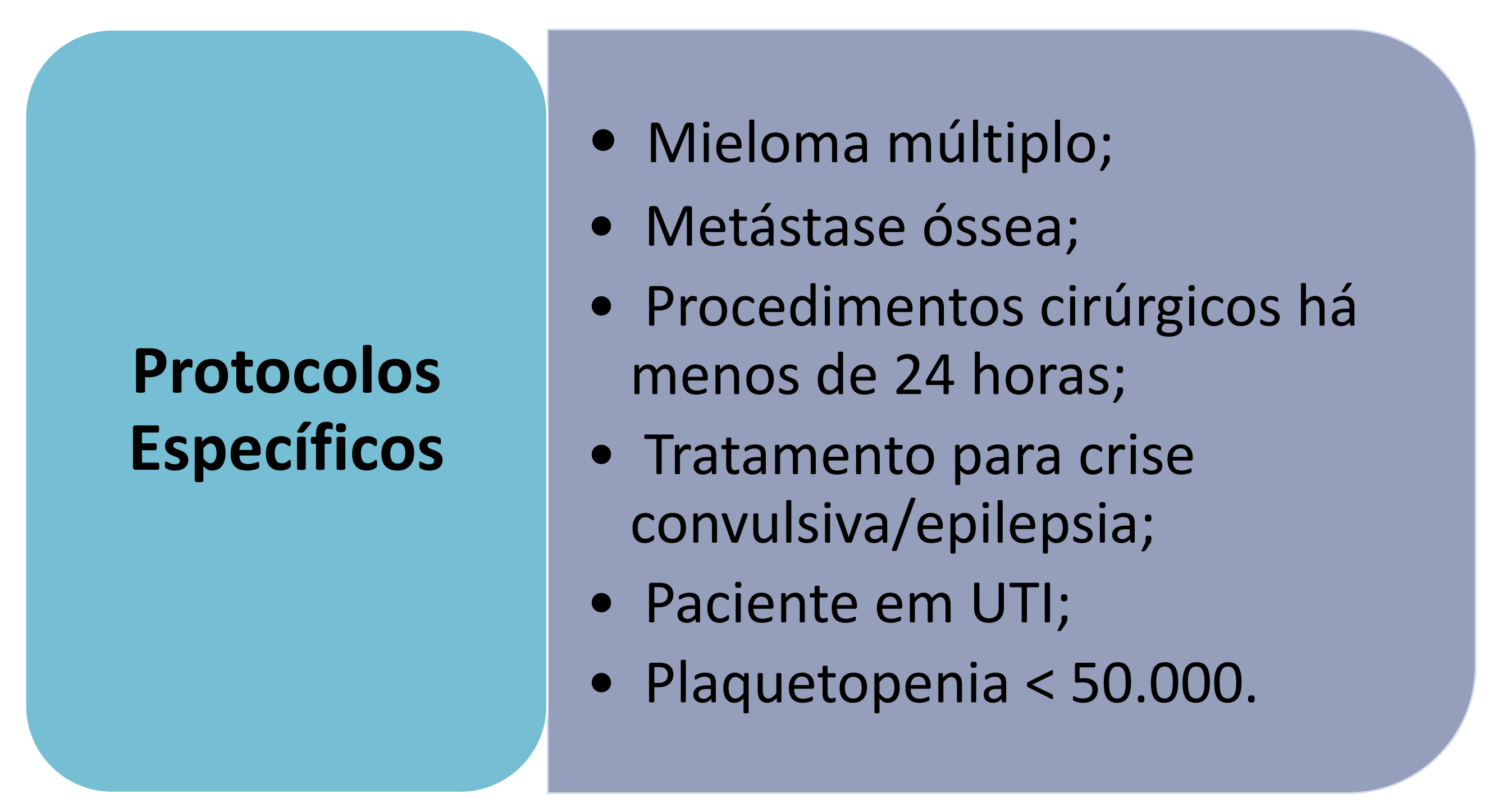

Foi realizado o projeto de Tutoria de Aplicação da Escala JHFRAT nos meses de maio-julho/ 2018 com acompanhamento in loco da avaliação do risco de queda com o enfermeiro da unidade.

\section{Conclusão}

A auditoria possibilitou a identificação das fragilidades na compreensão de cada critério da JHFRAT e capacitação dos enfermeiros para as novas definições. 